Abstracta Iranica Abstracta Iranica

Revue bibliographique pour le domaine irano-aryen

Volume 25 | 2004

Comptes rendus des publications de 2002

\title{
«Between the State and Cultural Zones: Nation Building in Turkmenistan ». Central Asian Survey 21/1, (2002), pp. 71-90.
}

\section{Bayram Balci}

\section{(2) OpenEdition}

1 Journals

Édition électronique

URL : http://journals.openedition.org/abstractairanica/5193

DOI : 10.4000/abstractairanica.5193

ISSN : 1961-960X

Éditeur :

CNRS (UMR 7528 Mondes iraniens et indiens), Éditions de l'IFRI

Édition imprimée

Date de publication : 15 mai 2004

ISSN : 0240-8910

Référence électronique

Bayram Balci, « «Between the State and Cultural Zones: Nation Building in Turkmenistan ». Central Asian Survey 21/1, (2002), pp. 71-90. », Abstracta Iranica [En ligne], Volume 25 | 2004, document 339, mis en ligne le 15 mars 2006, consulté le 25 septembre 2020. URL : http://journals.openedition.org/ abstractairanica/5193; DOI : https://doi.org/10.4000/abstractairanica.5193

Ce document a été généré automatiquement le 25 septembre 2020

Tous droits réservés 


\title{
«Between the State and Cultural
} Zones: Nation Building in Turkmenistan ». Central Asian Survey
21/1, (2002), pp. 71-90.

\author{
Bayram Balci
}

1 Consacré à la construction nationale au Trukménistan depuis 1991, l'article n'oublie pas que les fondements idéologiques de ce processus ont été jetés pendant la période soviétique. Parmi les principaux moyens mobilisés, l'A. note le recours aux médias, la construction d'une nouvelle historiographie, la remise au goût du jour de certains héros du passé lointain (comme le poète Makhtum-Quli). La méthode turkmène entre ainsi dans le cadre de ce que Benedict Anderson appelle le «modèle du nationalisme officiel»: un nationalisme construit par le haut. Cependant les enseignements d'Anderson sont ici insuffisants, selon l'A., qui suggère l'adoption de pistes supplémentaires, appelées « zones de contacts».

2 Ces zones de contacts ne sont autres que les influences culturelles étrangères, que l'A. évalue au nombre de quatre: russe, "islamique», turque et occidentale. L'influence slave se manifesterait par le rôle encore considérable des écoles et des médias en langue russe (toute chose à prendre avec réserve, compte tenu de la politique de dérussification menée depuis dix ans). Par influence islamique, on fait allusion au renouveau religieux encouragé par le pouvoir (certes la nouvelle identité turkmène peut, par le biais de ces réformes, acquérir une dimension islamique mais de là à soutenir qu'une identité "plus musulmane» engendre ipso facto une conscience nationale, il y a un pas que l'A. franchit avec un peu d'empressement). L'influence exercée par la présence culturelle turque (télévision, écoles privées et publiques) peut effectivement véhiculer la nouvelle idéologie nationale mise en chantier depuis 1991 mais le faible poids des établissements scolaires turcs leur permettra-t-il de jouer un rôle décisif en cette matière? Enfin l'influence occidentale, matérialisée par l'enseignement de l'anglais dans toutes les régions du pays et l'envoi d'étudiants à 
l'étranger contribuerait également à cette construction nationale, selon l'A. - qui surestime beaucoup l'exposition du pays à l'influence extérieure: de nos jours comme pendant la période soviétique, le Turkménistan reste le pays le plus fermé de la région.

Par ailleurs, si nombre de mesures prises depuis 1991 s'expliquent par cette volonté de Turkmenbachi de doter son peuple d'une conscience nationale, la politique nationale turkmène semble relever d'objectifs plus prosaïques: renforcer le pouvoir du chef récemment élu Prophète par son parlement; objectif atteint puisque le parlement a approuvé une récente loi dotant le pays d'un nouveau calendrier dont le premier mois s'appelle... Turkmenbachi.

INDEX

Thèmes : 13.3. Asie centrale

\section{AUTEURS}

BAYRAM BALCI

IFEA - Istanbul 